\title{
Minor surgery procedures: A retrospective review and prospective survey in a pediatric population
}

\author{
Emily Chan BHSc, Marija Bucevska MD, Cynthia Verchere MD FRCSC
}

\author{
E Chan, M Bucevska, C Verchere. Minor surgery \\ procedures: A retrospective review and prospective \\ survey in a pediatric population. Plast Surg \\ 2015;23(3):189-194.
}

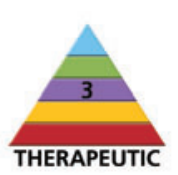

OBJECTIVE: The present study evaluated minor surgery procedures undertaken by a single plastic surgeon at BC Children's Hospital (Vancouver, British Columbia) for patient and physician satisfaction, parent impressions, psychological concerns and complications.

METHODS: Data were collected from a retrospective chart review and a prospective patient survey. Eligible subjects for the retrospective study included all pediatric patients undergoing minor surgery between May 2011 and April 2013. Parameters of interest included patient demographics, minor surgery specifics, complications and outcomes. Eligible subjects for the prospective patient survey included consecutive patients undergoing minor surgery between June 2013 and August 2013, as well as their parents.

RESULTS: A total of 219 procedures were included in the retrospective review. The mean age of subjects was 13.1 years (range two weeks to 18 years). The median length of follow-up was 46 days (range four to 606 days). There were no major complications; however, 45 minor complications in 36 patients were found. Complications included crusting (4.6\%), delayed wound healing (3.2\%), hypersensitivity (2.3\%), scar hypertrophy $(1.8 \%)$, infection $(0.9 \%)$ and other $(7.8 \%)$. Outcomes were categorized as one of four outcomes: both satisfied $(89.9 \%)$; patient satisfied but physician unsatisfied (0.8\%); patient unsatisfied and physician satisfied (3.1\%); and both unsatisfied (6.2\%). In the prospective study, 32 subjects consented to participate in the survey. Of these subjects, 10 children and 12 parents responded to the questionnaires. Eighty-three percent of respondents indicated that their goals were accomplished by their procedure and that they would be willing to undergo minor surgery again.

CONCLUSION: Minor surgery is possible and practical in pediatric plastic surgery clinics, with few complications and high patient and surgeon satisfaction.

Key Words: Local anesthesia; Minor procedures; Minor surgery; Outpatient surgery; Pediatric plastic surgery

\author{
Les interventions chirurgicales mineures : une \\ analyse rétrospective et un sondage prospectif \\ auprès d'une population d'âge pédiatrique
}

OBJECTIF : La présente étude visait à évaluer la satisfaction des patients
et des médecins, les impressions des parents, les inquiétudes psychologiques
et les complications après des interventions chirurgicales mineures, toutes
effectuées par le même praticien au BC Children's Hospital de Vancouver.
MÉTHODOLOGIE : Les chercheurs ont fait l'analyse rétrospective des
dossiers et effectué un sondage prospectif auprès des patients pour colliger
les données. Tous les patients d'âge pédiatrique qui avaient subi une chirur-
gie mineure entre mai 2011 et avril 2013 étaient admissibles à l'étude
rétrospective. Les paramètres d'intérêt incluaient la démographie des
patients, les particularités des chirurgies mineures, les complications et les
résultats cliniques. Les patients consécutifs qui avaient subi une chirurgie
mineure entre juin 2013 et août 2013, de même que leurs parents, étaient
admissibles au sondage prospectif. RÉSULTATS : Au total, 219 interventions ont fait partie de l'analyse rétrospective. Les sujets avaient un âge moyen de 13,1 ans (plage de deux semaines à 18 ans) et ont profité d'un suivi médian de 46 jours (plage de quatre à 606 jours). Ils n'ont pas souffert de complications majeures, mais les chercheurs ont constaté 45 complications mineures chez 36 patients, soit la formation de croûte $(4,6 \%)$, le retard de cicatrisation de la plaie (3,2\%), l'hypersensibilité (2,3\%), l'hypertrophie cicatricielle (1,8\%), l'infection $(0,9 \%)$ et d'autres problèmes $(7,8 \%)$. Les résultats cliniques ont été divisés en quatre possibilités : médecin et patient satisfaits (89,9\%); patient satisfait, mais médecin insatisfait $(0,8 \%)$; patient insatisfait et médecin satisfait (3,1\%); et médecin et patient insatisfaits (6,2\%). Dans l'étude prospective, 32 sujets ont consenti à participer eu sondage. De ce nombre, dix enfants et 12 parents ont répondu aux questionnaires, et $83 \%$ des répondants ont indiqué que l'intervention avait atteint le but visé et qu'ils seraient prêts à subir une nouvelle chirurgie mineure.

CONCLUSION : Il est possible et faisable d'effectuer des chirurgies mineures dans les cliniques de chirurgie plastique pédiatrique. Elles entraînent peu de complications, et les patients et les chirurgiens en sont fort satisfaits.
$\mathrm{T}$ he shift in practice from pediatric inpatient surgery to outpatient surgery emerged in the early 20th century, to promote cost effectiveness and reduce the negative psychological effects associated with hospitalization (1). The concept of day-care surgical procedures was advanced in the late 1960s with the development of ambulatory surgery units in which regional anesthesia was used (2). These clinics were friendly, easily accessible and had become a necessity to reduce excessive wait times for surgery (2).

Today, outpatient minor surgery using local anesthesia may be increasingly preferred for management of small lesions, scars and biopsies in the pediatric population. Recent studies have shown that the use of regional or local anesthesia techniques can limit adverse events and improve patient outcomes in surgery (3). It has also been demonstrated that wait times for surgery and the costs of minor surgical procedures can be reduced by up to two and 3.8 times, respectively, when performed in a hospital ambulatory setting instead of the operating room (4-6).
Despite this evidence, there is a lack of current literature focusing on minor surgery procedures both in the pediatric population and ambulatory clinics. Anecdotally, some surgeons are hesitant to offer local anesthesia procedures to younger patients because of concerns about patient or parent anxiety, unpredictability of time commitment to a case, patient compliance/cooperation at the time of surgery, and patient pain tolerance. On the other hand, some will routinely perform pediatric otoplasties and complex hand surgery in the outpatient setting $(7,8)$. In our clinic, minor surgery under local anesthesia is routinely recommended for small procedures in children older than five or six years of age if, after an informal screening interview at the time of consultation, they and their parents agree that it is reasonable.

Screening is initiated at the time of consultation. Most preteens and teens will be the primary interviewee, with age-appropriate questions and explanations directed to them face to face from the beginning of the consult. Parents are included secondarily if they have questions or 
if the patient defers to them. The patient will often decide whether to go ahead with the procedure. Except for newborns, patients $\leq 4$ years of age are usually considered for minor surgery only on rare occasions. In young children $\geq 5$ years of age, especially if the child is shy or quiet, the parent is usually asked in an oblique way whether they believe from previous experience their child may be a candidate for a minor surgery procedure. Questions to the parent may include their child's reaction/experience with vaccinations, dental work, medical examinations or suture of lacerations. It may be obvious at that point that a child will not be a good candidate for elective local anesthesia, and if there is no urgency for the procedure, sometimes waiting a year may be recommended. Anecdotally, it appears that girls may reach a local anesthesia mature age earlier than boys.

We do not usually explain anything in detail to the child if we are not planning something imminently. If a parent does not express a concern that going forward would be a poor decision, then attention is turned back directly to the child, and face-to-face discussion ensues, almost excluding the parent. The senior author has learned from experience several phrases and approaches that allow for good preparation, and several words not to use. An example of this screening/ preparation conversation to a younger child follows:

We all think that we should take your mole off of your arm. Do you think that is okay? (presume a nod).

I have some magic medicine that goes underneath the mole that makes that whole mole go right to sleep. You would be awake, but your mole would be totally asleep. It's asleep soooo deeply that I can poke it, scratch it, and even cut it and you wouldn't even feel it all. So I can take it off, and put stitches in it without it hurting. Would that be okay? (presume another nod).

Okay, the ONLY part you would feel is at the very beginning, when I put the magic medicine in. Because I have to put it UNDER the mole, you would feel a small poke and a sting for about three seconds right at the beginning. Once that part is done, you won't feel anything more. Do you think you can handle that?

There are a few things that we can do to make even that part easier. I promise NEVER to sneak up on you, and I will tell you exactly when everything will happen. I will count to three and you can take a big breath and blow really hard for the few seconds that it stings a little. Then it's done.

The child's reaction to or participation in this discussion may provide assurance or discouragement to proceed. Tears, withdrawal to the parent, significant anxiety or verbal expression of nonassent may contribute to a 'negative' screening and parents are advised either about local anesthesia with oral sedation, general anaesthesia, or maturation of approximately one year or so if nonurgent. Often, the child will be nervous, but willing to go ahead, and a date for minor surgery is booked, usually within several weeks or when sports/activity schedules allow for recovery time. In younger children, in whom extra encouragement may be helpful, we have a 'prize drawer' with some incentive gifts. They are offered a chance to pick a toy or prize that we put their name on, and save in a safe place for when they return for their procedure to be completed.

Parents may interject the interview with certain words or phrases that they believe are helpful but are truly not, such as 'needle' or 'knife' or 'shot'. Surgeon positioning and body language during the face-to-face interview with the child may allow one to be the primary source of information to the child, and deflect or discourage parent participation until the discussion is finished. We know we cannot control discussion that occurs at home after the consult, but if the initial explanation ends with child assent, usually the procedure will be successfully completed.

Our centre has a dedicated minor procedure room equipped with a procedure light, procedure table, and basic plastic surgery instrument packs and sutures. There is no nurse assistant or housekeeping resource.
Most commonly, the surgeon, the patient, and one or both parents are in the room, occasionally with a trainee. Usually, trainees are not the primary surgeon on younger patients. Parents are told that they are welcome to come in, but if they would rather not, they do not have to. Sitting down in chairs is mandatory because experience shows up to approximately $20 \%$ may have moments of feeling uncomfortable or lightheaded.

Usually, cases are scheduled for approximately $30 \mathrm{~min}$ for a single small excision procedure, $45 \mathrm{~min}$ for two or three lesions, and up to $1 \mathrm{~h}$ for more complex cases or more anxious patients. This time includes verbal preparation time, instillation of local anesthesia, dressing application, and postoperative discussion and care instructions. Patients with uncomplicated procedures are asked to follow up at approximately six weeks postoperatively, and are usually invited to follow up at one year. Patients who travel long distances or who have difficulty attending an appointment are invited to follow up if there are problems, or electronically if they are comfortable with that method. We specifically tell all of our patients that if they do not follow up, or do not contact us with further information, we will assume that they are completely satisfied with the outcome. Pathology results are always copied to the referring physician and/or family doctor. Any significant pathology findings are reviewed at follow-up, and patients with important pathology will be called to attend an appointment if they have not followed up on their own.

With respect to the actual procedure, routines have been developed over the years to allow for the maximal completion rate. Especially in staged serial excisions, priority is given to making the procedure as minimally traumatic as possible so the patient will return for the next stage.

EMLA (AstraZeneca Canada Inc) is recommended for some patients, but it is our experience that it helps only minimally with the instillation of anesthesia, and often it is placed by the parent in an area remote to the injection site or not left on for a sufficient time. It may reduce the injection entrance pain, but it does not reduce the subcutaneous stinging, which is more significant. If using or recommending EMLA, it must be made clear beforehand that there will still be some stinging; otherwise parents often will mistakenly assure the patient they will feel nothing. We have also used some skin refrigerant spray at the time of injection in some patients but have had mixed responses to the intense cold produced.

We have a screen mounted on the ceiling if patients want to watch a video, but in actuality this is rarely used. Patients may bring with them music or electronic devices for distraction, and parents are encouraged to bring books or stories in which their child may want to engage. If ear buds are used, it is important that the child can still hear your voice. We usually keep a stack of joke books, most of which are pretty 'lame', to have parents read to their children, providing distraction to both parties. The senior surgeon may tell jokes or sing songs on occasion, which provides distraction; however, more often discussions about birthdays, school activities, sports and siblings provide a running commentary throughout the procedure.

Before the injection, the order of the procedure is briefly reviewed with the child and parent(s), the explanation of feeling a small poke and sting is reiterated, and practice breaths and blowing are often undertaken. Any previously chosen prizes are brought into the room to be in view and provide incentive. The promise is kept that the patient will not be surprised by anything, and a count of three is made to prepare for injection. Calm, confident, friendly, unrushed but steady progress is maintained while proceeding with injection, and delays are discouraged. There is an empathetic response to tears or crying, but after injection, distraction with conversation, redirection and patient self-testing of the site of injection is undertaken, and the procedure usually proceeds easily once the child has confidence in the freezing.

It was our impression that in our practice, using these techniques, we may be completing more local anesthesia procedures in children than what our training inferred was possible. We wanted to review our actual procedure data. The objective of the present study was to 


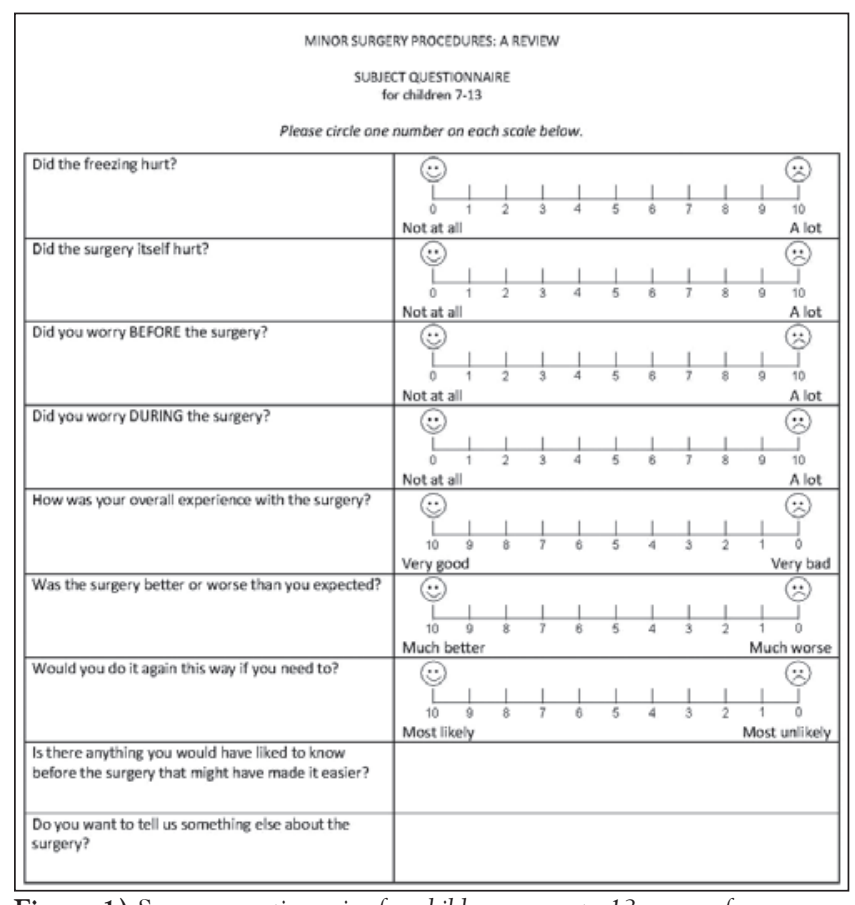

Figure 1) Survey questionnaire for children seven to 13 years of age

review a snapshot of our experiences with minor plastic surgery procedures in the plastic surgery unit at BC Children's Hospital $(\mathrm{BCCH})$, Vancouver, British Columbia. We report our findings regarding patient and physician satisfaction, parent impressions, psychological concerns and complications.

\section{METHODS}

The present study was designed with two components: a retrospective chart review and prospective patient survey. Ethics approval was granted by the University of British Columbia Children's and Women's Research Ethics Board (\#H13-01436).

\section{Retrospective chart review}

- Patients $\leq 18$ years of age who had undergone minor surgery under local anesthetic without sedation between May 1, 2011 and April 30, 2013 were considered to be eligible. All procedures were performed by the senior author in the $\mathrm{BCCH}$ plastic surgery ambulatory clinic. Patients with unavailable records were excluded from the study. Patient charts were retrospectively reviewed for patient demographics, diagnosis, surgical procedure, local anesthetic administered, length of follow-up, complications and outcome. All procedures were evaluated as independent events.

- Data from patient charts were entered into a database and analyzed using summary statistics in Excel (Microsoft Corporation, USA). Mean, median and range were reported for age and length of follow-up. Complication rates were calculated as a percentage of total procedures. Patient and physician satisfaction recorded during follow-up appointments were used as the outcome measurement. For subjects with multiple visits during the study period, age at the first recorded visit in the study period was considered for the calculation of cohort age. Missing data are reported in the text. Handling of missing values in outcome calculations is explained in the results section.

\section{Prospective patient survey}

- Consecutive patients $\leq 18$ years of age undergoing minor surgery under local anesthetic within the period of June 12, 2013 to August 31, 2013 were approached and invited to participate in the ad hoc survey. Parents of eligible patients were also invited into the study. Consent was obtained in the waiting room before the minor surgery

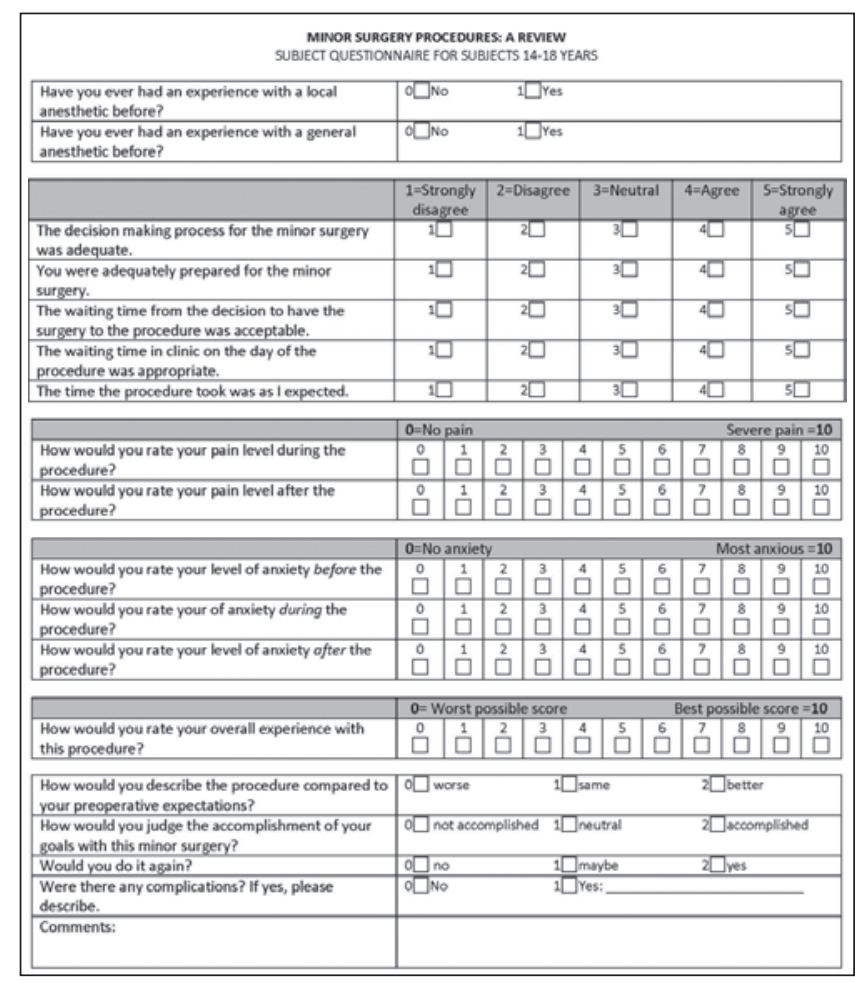

Figure 2) Survey questionnaire for children 14 to 18 years of age

was performed. Study participants were offered a questionnaire to complete within one to two weeks following the minor surgery procedure via mail, e-mail or telephone interview. If no response was given by two weeks after the questionnaires were sent out, one follow-up email or telephone call was made to the participants as a reminder.

- All participants had their minor surgery procedure performed by the senior author in the $\mathrm{BCCH}$ plastic surgery clinic.

- Three questionnaires used in the survey were developed ad hoc for the purpose of the study. The questionnaires used representative versions of the same questionnaire adjusted for age: questionnaire for subjects seven to 13 years of age (Figure 1), 14 to 18 years of age (Figure 2) and parents (Figure 3). The questionnaire for children 14 to 18 years of age was identical to the parent questionnaire, except the terms 'you' and 'your' were replaced with 'your child' and 'your child's'. These age groups correspond to the standard age ranges for assent and consent forms set by the research ethics board.

- Data were analyzed using descriptive statistics, and parental or patient 'comments' were analyzed qualitatively.

\section{Retrospective chart review}

\section{RESULTS}

In total, 174 pediatric patients undergoing minor surgery procedures in the study period were identified. Three patients who underwent conscious sedation in the emergency room for their procedure and three patients with missing records were excluded. The final study cohort included 168 subjects, 68 of whom were male and 100 were female. Mean and median ages were 12.8 years and 13.2 years, respectively, ranging from two weeks to 18 years. The distribution of age according to sex of the study population is shown in Figure 4. Notably, 28\% of the study population were patients $\leq 10$ years of age.

A total of 168 subjects underwent 219 minor surgery procedures. Of those subjects, 134 underwent a single procedure and 34 underwent multiple procedures performed within the study period. From those who underwent multiple procedures, 23 subjects underwent $\geq 2$ procedures performed in the same visit, while 11 subjects had minor surgeries performed during different clinic visits. The most frequently performed 


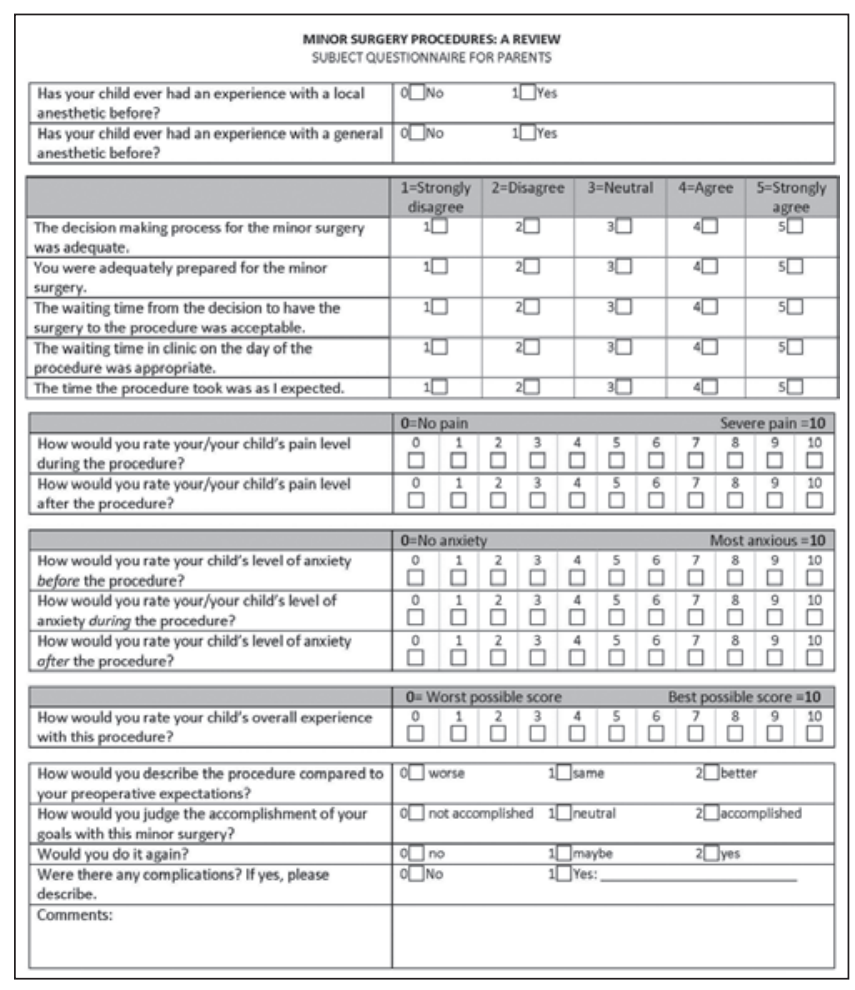

Figure 3) Survey questionnaire for parents

procedure was simple excision $(n=164)$, followed by serial excision $(n=21)$, simple revision $(n=21)$, complex revision $(n=9)$, complex excision $(n=3)$ and suture removal $(n=1)$.

Primary diagnoses for the 219 procedures were nevus $(n=137)$, scar $(n=27)$, benign tumour $(n=18)$, congenital deformity $(n=13)$, cyst $(n=10)$, malignancy $(n=2)$, acquired deformity $(n=5)$ and other $(\mathrm{n}=7)$.

More than $97 \%$ of procedures $(n=213)$ were performed using $1 \%$ lidocaine with epinephrine. The remaining $3 \%$ of procedures were performed using either $2 \%$ lidocaine with epinephrine, plain $1 \%$ lidocaine or plain $2 \%$ lidocaine.

There were no follow-up visit records for 70 procedures. Of the remaining 149 procedures, length of follow-up ranged between four and 606 days, with a mean of 68 days and median of 47 days. Complications of the minor surgery procedure as well as patient and physician satisfaction were recorded over these follow-up visits.

Undesirable postoperative events were classified as major or minor complications. There were no major complications, defined as events that pose risk to life or limb (9), in any of the procedures. Minor complications, however, were reported in 36 of 219 total procedures.

Minor complication rates were divided into the following categories: crusting $(4.6 \%)$, delayed wound healing (3.2\%), hypersensitivity reactions $(2.3 \%)$, scar hypertrophy $(1.8 \%)$, infection $(0.9 \%)$ and other complications (7.8\%) (Table 1). Crusting was defined as a persistence of crust on the incision at follow-up, sometimes overlying an area of mildly delayed wound healing. Crusts were allowed to separate on their own and were generally treated with topical ointment until healed. Wound dehiscence was not included in this group. Some patients complained of prolonged sensitivity of the incision six weeks postoperatively despite a well-healed wound. In children, this reaction was defined as hypersensitivity, and active massage and stimulation of the wound generally allowed resolution. 'Other' complications included suture granulomas, bleeding, broken sutures and drainage issues.

The surgical outcomes for all procedures were assessed according to patient and physician satisfaction during the follow-up visit. Of the 149 procedures with follow-up records, there was an explicit statement

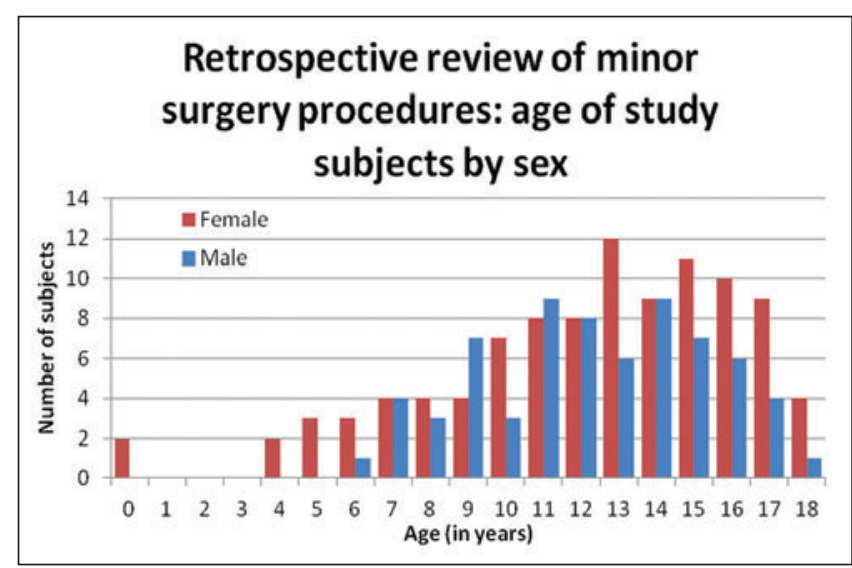

Figure 4) Age and sex distribution of research subjects in the retrospective component of the study

of satisfaction regarding the outcome by both the patient and physician for 129 procedures. The remaining 20 surgical procedures did not have a reported outcome in their charts, although follow-up records existed. These procedures were reported with an unknown outcome and excluded from the outcome satisfaction analysis. The 129 recorded outcomes were categorized under four possibilities (Table 2): both patient and physician satisfied (89.9\%); patient satisfied and physician unsatisfied $(0.8 \%)$; patient unsatisfied and physician satisfied $(3.1 \%)$; and both unsatisfied (6.2\%). Primarily, dissatisfaction was with poorer than expected aesthetic outcome.

The impact of the 70 patient procedures that did not have formal follow-up was difficult to assess. If the worst possible outcome was assumed and the 70 procedures with no follow-up were categorized as having all had an unsatisfactory outcome, then patient and surgeon satisfaction would be attributed to 116 of 199 subjects (58.3\%). If the best possible outcome was assumed for all of those procedures, (70 of 70 being satisfied), the outcome analysis would show patient and surgeon satisfaction in 186 of 199 patients (93.5\%). If the satisfaction rate in the 70 unfollowed procedures was assumed to be similar to the pool of patients who did follow up $(89.9 \%)$, then the overall patient and surgeon satisfaction rate would be 179 of 199 , or $89.9 \%$; this was believed to be the most sensible scenario to report in Table 2, despite explicit instructions to patients that if they did not follow up, complete satisfaction would be assumed.

\section{Prospective patient survey}

Consent was obtained from 35 of 39 invited participants for the study. Four participants declined due to language difficulties. Of those who consented, 22 subjects successfully completed the questionnaires: four children seven to 13 years of age, six children 14 to 18 years of age, and 12 parents. Median age of patients undergoing a procedure was 13 years, ranging from four weeks to 18 years. There was an equal ratio of female to male subjects that participated in the present survey. The mean response time to complete and return the questionnaires was 17.5 days, ranging from five days to 5.5 weeks.

Children seven to 13 years of age: Four survey questionnaires were completed by children seven to 13 years of age. Their responses indicated that the freezing hurt at a mean level of 6 of 10 (range 2 to 9), while the surgery itself did not hurt (2.8 of 10 [range 0 to 9]). The children's level of worry before surgery was at an average of 2.5 of 10 (range 0 to 5 ), and during surgery was 3.8 of 10 (range 1 to 8 ). Their overall experience with the surgery was very good with a mean of 9 of 10 (range 7 to 10 ), and the surgery was better than expected ( 8.8 of 10 [range 8 to 10]). All four children answered they would most likely do it again if they need to (mean response 10 of 10 ).

Children 14 to 18 years of age: Six children 14 to 18 years of age returned the completed survey questionnaire. Five reported having previous experience with local anesthesia and two reported previous 
TABLE 1

Minor complications according to type of procedure in the retrospective study

\begin{tabular}{|c|c|c|c|c|c|c|}
\hline Procedure & Infection & Hypersensitivity & Scar hypertrophy & Delayed wound healing & Crusting & Other* \\
\hline Simple excision $(n=164)$ & 1 & 2 & 1 & 4 & 7 & 9 \\
\hline Serial excision $(n=21)$ & 0 & 0 & 1 & 0 & 3 & 5 \\
\hline Complex excision $(n=3)$ & 0 & 0 & 0 & 0 & 0 & 0 \\
\hline Complex revision $(n=9)$ & 1 & 0 & 1 & 2 & 0 & 0 \\
\hline Suture removal $(n=1)$ & 0 & 0 & 0 & 0 & 0 & 1 \\
\hline Overall rate, $\%$ & 0.9 & 2.3 & 1.8 & 3.2 & 4.6 & 7.8 \\
\hline
\end{tabular}

Data presented as $n$ unless otherwise indicated. *Includes suture granulomas, bleeding, broken sutures and drainage

experience with general anesthesia. On a scale of 1 to 5 , in which 1 was 'strongly disagree' and 5 was 'strongly agree', the survey responders agreed the decision-making process for the minor surgery was adequate (4.3); they were adequately prepared for the minor surgery (3.8), the wait time from decision to procedure was acceptable (4.5); the wait time in clinic on the day of procedure was acceptable (4.5) and the time the procedure took was as they expected (4.7). The pain level during the procedure averaged 2.3 of 10 , and was slightly higher after the procedure, averaging at 3.8 of 10 . On a scale of 0 to 10 , in which 10 was the highest possible score, the level of anxiety was the highest before the procedure (mean 6.3, range 0 to 10 ) followed by a mean score of 4.3 during the procedure (range 1 to 10 ) and the lowest at a mean level of 1.8 after the procedure (range 0 to 6 ).

The survey respondents in the age group 14 to 18 years indicated that the overall experience with minor surgery was positive with a mean score of 8.2 of 10 (range 5 to 10). Four participants described the procedure as 'better' compared with their preoperative expectations, one participant described it as 'same' and one participant marked it as 'worse'. Four participants indicated their goals were accomplished successfully by minor surgery, one was neutral and one did not answer, adding a comment "too early to tell". Five of six respondents indicated they "would do it again", and one participant indicated they would not. Five of six had no complications and one indicated it was too early to report.

Parents: Twelve parents returned the completed survey questionnaire. Seven of these reported having previous experience with local anesthesia and four reported previous experience with general anesthesia. Similar to the children aged 14 to 18 years, on a scale of 1 to 5 where 1 was 'strongly disagree' and 5 was 'strongly agree', the parents agreed the decision-making process for the minor surgery was adequate (4.7); their children were adequately prepared for the minor surgery (4.7); the waiting time from decision to procedure was acceptable (4.5); the waiting time in clinic on the day of procedure was acceptable (4.7); and the time the procedure took was as they expected (4.9). The pain level during the procedure averaged 1.6 of 10 (range 0 to 5), and was slightly higher after the procedure averaging at 2.3 of 10 (range 0 to 9) from parent's perspective. On a scale of 0 to 10 where 10 was the highest possible score, their child's level of anxiety was the highest before the procedure (mean 4.3, range 0 to 10 ) followed by a score of 3 during the procedure (range 1 to 10 ) and the lowest at 1 after the procedure (range 0 to 4 ).

The parents rated their child's overall experience with minor surgery as positive with a mean score of 9.3 of 10 (range 8 to 10). Seven of the surveyed parents rated the procedure as 'better' compared withtheir preoperative expectations and 5 rated it as 'same'. When asked whether their goals were accomplished successfully by the minor surgery, 11 of 12 parent respondents said "yes", while one did not answer. Nine of the surveyed parents indicated they "would do it again", two said "maybe" and one participant did not respond. Five of six did not have any complications and one indicated it was too early to report. In 11 of 12 procedures, parents indicated there were no complications following the procedures.

Comparison of parent responses with the 14- to 18-year-old child responses showed no statistically significant differences in agreement level.
TABLE 2

Outcome analysis

\begin{tabular}{llll}
\hline & & \multicolumn{2}{c}{ Patient } \\
\cline { 3 - 4 } Surgeon & & Satisfied & Unsatisfied \\
& Satisfied & $116(89.9 \%)$ & $4(3.1 \%)$ \\
& Unsatisfied & $1(0.8 \%)$ & $8(6.2 \%)$ \\
\hline
\end{tabular}

The outcomes of 129 procedures with follow-up records, as measured by a combination of patient and physician satisfaction. Procedures that did not have follow-up data were not included in this analysis

Qualitative analysis: Three children seven to 13 years of age, three children 14 to 18 years of age and seven parents provided narrative comments that were analyzed qualitatively using positive or negative categories. Most (12 of 13) of the comments expressed positive experience, acknowledging the surgeon, the staff and/or showing gratitude and emotional satisfaction. One parent commented: "Most satisfactory outcome, son is happier, doctor was professional". One child expressed "I don't think I could have had a better job done. I'm happy." One of the participants addressed the need for more information beforehand, although they were satisfied overall. "Would have liked to known more of the steps (would have calmed me down). Having mom in the room was nice. Friendly chatter during the procedure was comforting. Playing music in the operating room would be nice as well. Overall, I was very satisfied!" The negative comment indicated "patient was stressing out because doctor was running behind schedule".

\section{DISCUSSION}

Minor surgery can be performed in a variety of settings including primary care offices, hospital ambulatory clinics and the operating room. Previous research has recommended that a hospital-based minor surgery unit is more cost effective than procedures undertaken in either the operating room or in general practice. Furthermore, a prospective trial published in 2008 (10) showed that the quality and safety of minor surgery performed by specially trained hospital physicians is higher than those carried out in primary care practices.

The present study supports the practice of minor surgery in hospitalbased pediatric ambulatory clinics for patients screened to be appropriate candidates. We found that a significant proportion of procedures performed in the $\mathrm{BCCH}$ plastic surgery clinic resulted in satisfactory outcomes for both the patient and physician. In addition, there were no major complications, and minor complications were uncommon. Infection, significantly, occurred in $<1 \%$.

In past years, surgeons have often hesitated to perform minor surgery in children $<10$ or 11 years of age. However, in our practice, we have noted that a significant proportion of our pediatric population younger than this underwent successful procedures in the ambulatory clinic. Minor surgery is feasible in children as young as five or six years of age, and can be an appropriate and positive treatment option.

Hospital outpatient clinics may become the preferred vehicle for the delivery of minor surgery services. These clinics, regularly available, offer the ability to form personal relationships with staff and surgeon, which may contribute to the high degree of patient satisfaction. 
With the present snapshot review, we conclude that performing minor procedures on appropriate pediatric patients under local anesthesia can be a practical and usually successful option for those who want to eliminate the risks of general anesthesia or sedation in the pediatric population. Appropriate screening, and confident and honest discussion in preparation for a child's procedure is mandatory. Distraction techniques and incentives that allow the patient, parent and surgeon to be comfortable should be encouraged and will likely vary with surgeon and patient character.

The present study supports the use of the minor surgery clinic to facilitate satisfactory outcomes in the pediatric population with minimal additional resources required.

\section{Limitations}

For the retrospective review, we were able to identify all patients scheduled for 'minor surgery' through the hospital patient scheduling system. However, it was possible that a few patients underwent minor surgery in their first assessment visit, which would be listed as a 'new patient appointment' in the scheduling system. We estimated that six or seven patients may have been missed in the consecutive collection of data for that reason.

Due to the aforementioned style of practice in our clinic, followup visits were not arranged by a number of our patients. The lack of follow-up, as well as some nonspecific recordings of patient and surgeon satisfaction, limited the outcome analysis. Making the assumption that patients satisfied with their outcome did not schedule or attend a follow-up visit, and subsequently categorizing them as having a satisfactory outcome, can only appear to be speculation. However, this is probably close to reality, considering our instructions. If the patients with no follow-up are excluded from the outcome analysis, there is no significant difference in the calculated patient and physician satisfaction levels $(93.5 \%$ versus $89.9 \%$ with no-follow up excluded).

In the prospective survey, the main limitation was that only $56 \%$ of subjects that consented to participate in the study completed the questionnaires. Thus, we had a more limited data set for analysis.
The design of the present study was also sussceptible to recall bias, in that there was a range of response times to the questionnaires (five days to 5.5 weeks). Recall of information based on memory of the minor surgery may become more unreliable with time and our survey was not validated. As well, patients responding at different stages of healing might have different perceptions of the surgery's success.

\section{REFERENCES}

1. Moir CR, Blair GK, Fraser GC, Marshall RH. The emerging pattern of pediatric day-care surgery. J Pediatr Surg 1987;22:743-5.

2. Calnan J, Martin P. Development and practice of an autonomous minor surgery unit in a general hospital. Br Med J 1971;4:92-6.

3. Capdevila X, Ponrouch M, Morau D. The role of regional anesthesia in patient outcome: Ambulatory surgery. Tech Reg Anesth Pain Manag 2008;12:194-8.

4. Leblanc MR, Lalonde J, Lalonde DH. A detailed cost and efficiency analysis of performing carpal tunnel surgery in the main operating room versus the ambulatory setting in Canada. Hand (N Y) 2007;2:173-8.

5. Salam MA, Matai V, Salhab M, Hilger AW. The facial skin lesions "see and treat" clinic: A prospective study. Eur Arch Otorhinolaryngol 2006;263:764-6.

6. Bandyopadhyay D, Turnpenny B, Dewar EP. Direct access minor surgery service - patient satisfaction and effectiveness. Ann R Coll Surg Engl 2005;87:248-50.

7. Caouette-Laberge L, Guay N, Bortoluzzi P, Belleville C. Otoplasty: Anterior scoring technique and results in 500 Cases. Plast Reconstr Surg 2000;105:504-15.

8. Lalonde D, Bell M, Benoit P, Sparkes G, Denkler K, Chang P. A multicenter prospective study of 3,110 consecutive cases of elective epinephrine use in the fingers and hand: The Dalhousie Project Clinical Phase. J Hand Surg 2005;30:1061-7.

9. Pyle JW, Angobaldo JO, Bryant AK, Marks MW, David LR. Outcome analysis of a resident cosmetic clinic: Safety and feasibility after 7 years. Aesthet Surg 2010;64:270-4.

10. George S, Pockney P, Primrose J, et al. A prospective randomised comparison of minor surgery in primary and secondary care: The MiSTIC Trial. Health Technol Assess2008;12: iii-iv, ix-38. 